
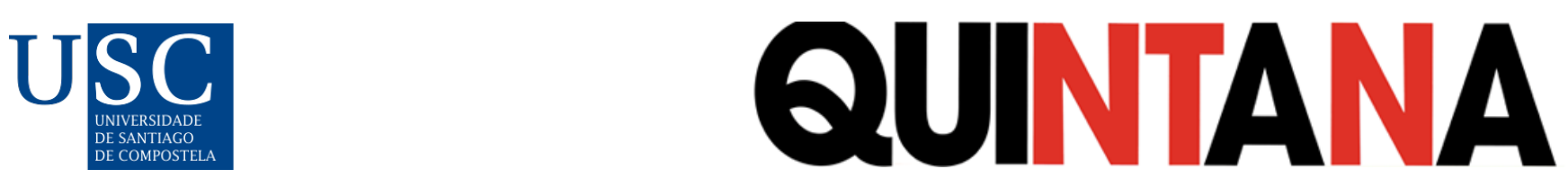

Quintana: revista do Departamento de Historia da Arte, (20), 2021. ISSN-e: 2340-0005

https://doi.org/10.15304/quintana.20.8062

Escritos sobre ...

\title{
SANTIAGO DE COMPOSTELA EN 1759. LA PROCLAMACIÓN DE CARLOS III EN LA AGUDA PLUMA DEL CURA DE FRUÍME, DIEGO CERNADAS DE CASTRO
}

SANTIAGO DE COMPOSTELA IN 1759. THE PROCLAMATION OF CHARLES III IN THE INGENIOUS WRITING OF THE CURA DE FRUÍME, DIEGO CERNADAS DE CASTRO

\author{
Alfredo Vigo Trasancos ${ }^{1, a}$, Julio Vázquez Castro ${ }^{2, b}$ iD \\ ${ }^{1}$ Universidade de Santiago de Compostela, España \\ ${ }^{2}$ Universidade de Santiago de Compostela, España \\ a lfredomanuel.vigo@usc.es b julio.vazquez@usc.es
}

El 11 de septiembre de $1759^{1}$, apenas un mes después del fallecimiento de Fernando VI en el castillo de Villaviciosa de Odón, se recibía en el Ayuntamiento de Santiago una carta-orden de la reina gobernadora, Isabel de Farnesio, urgiendo a la ciudad para que procediese a celebrar el acto público de proclamación de su hijo Carlos III como nuevo rey de España ${ }^{2}$.

Era un acto costoso que requería de una muy precisa organización y de unos recursos económicos importantes; por ese motivo, el Concejo compostelano, reunido ese día para dar respuesta a la orden real, no sólo determinó para la noche siguiente del día 12 organizar una iluminación universal de calles y plazas, el lanzamiento de fuegos y el repique general de todas las campanas en conmemoración del monarca, sino que procedió a dictar bando para dar a conocer su decisión a todo el vecindario y, asimismo, a despachar cartas a todas las autoridades públicas, entre las que se encontraban el arzobispo Bartolomé Rajoy, el cabildo y el provisor, la Universidad y los colegios de Fonseca y San Clemente, el administrador del Hospital Real, el Santo Oficio de Inquisición y todas la congregaciones religiosas que tenían su asiento en Compostela ${ }^{3}$.

Además, también se tomó la determinación de solicitar un préstamo de 36.000 reales para hacer frente a los festejos -se incluían en ellos los gastos previstos para las exequias que habrían de celebrarse en honor del monarca difunto- y de nombrar a las personas de la corporación que tendrían que llevar todas las cuestiones previstas para los actos de la proclamación que contemplaban tres días completos de fiestas: el primero para poder realizar una gran "máscara" o "pompa" presidida por una suntuosa carroza que habría de recorrer con el fasto necesario todo el itinerario urbano habitual en este tipo de festejos que tenían un protagonismo claramente civil, el segundo para celebrar el alzamiento oficial de los pendones en honor al nuevo rey, que contemplaban el montaje de tres "teatros" o tablados en las tres plazas en donde iban a efectuarse los alzamientos -ante el palacio arzobispal en Azabachería, en la plaza de Feijóo y en la plaza del Consistorio llamada del Campo-, todos culminados con los correspondientes vivas al rey, y el 
tercero para clausurar las fiestas de la proclamación con más luminarias y fuegos de artificio en una jornada parecida a la que se había establecido para el 12 de septiembre. A esto se añadía todo lo necesario para que un acto de tal trascendencia tuviese la dignidad necesaria, pues se requerían, en efecto, numerosas cabalgaduras para el cortejo, una vistosa carroza, ricas vestimentas para los participantes, músicos y coro, una partida de granaderos y obviamente un muy engalanado pendón con las armas reales para que pudiera ser visible y efectivo en su tremolar a la vista de todo el público ${ }^{4}$.

Se entiende, por tanto, lo crecido de los gastos y la necesidad del préstamo, que finalmente, fue ofrecido por un particular -Agustín Antonio Gutiérrez, vecino de la ciudad y Tesorero de Bulascon el corto interés del $6 \%{ }^{5}$. Solo quedaba, pues, fijar la fecha oficial para la "Real funcion de proclamacion y lebantamiento de Pendones en esta Capital, por el señor Rey don Carlos tercero", que quedó establecida para el día 14 de octubre; por esta razón el día 13 se estableció para la "máscara" y el día 15 para la fiesta final con luminarias y fuegos de artificio. Con esto se pondría fin a todos los festejos ${ }^{6}$.

Ahora bien, es seguro que, desde el principio, se pensó en dar a conocer al público el relato minucioso de las fiestas. De ahí que, una vez acabadas éstas, y tras acordar la corporación dar "quenta a la señora reina gouernadora, nuestra señora, con testimonio de auerse ejecutado la proclamacion" con "sumo aplauso"7 , a continuación se tomase la decisión de publicar la narración del evento, lo que se hizo, en efecto, al año siguiente, en $1760^{8}$, cuando salió a la luz el texto de la proclamación de la imprenta compostelana de Andrés Frayz, con sus 77 páginas de extensión, que se distribuyeron ampliamente entre los miembros más destacados del Concejo y la ciudad, de la Real Audiencia de A Coruña y de la propia Corte, dejando sólo "los que sobraren (y no más)" para que pudieran ser adquiridos por "la gente de ynferiores circunstanzias"”.

El relato había sido escrito por Diego Cernadas de Castro (fig.1), más conocido por su apodo de "cura de Fruíme", bajo el título: Carta-Quenta, ó razón en suma de las festivas gozosas demostraciones, con que la muy noble, y muy leal Ciudad de Santiago de Galicia, celebró la Solemne aclamación de nuestro rey, y señor Don Carlos III. Posteriormente se volvió a editar en el tomo V de las obras completas del autor, que se publicó en Madrid, en 1780, en la imprenta de Joachín Ibarra ${ }^{10}$. 
Fig. 1. Rodríguez: El cura de Fruíme D. Diego Antonio Cernadas y Castro. Grabado, en Obras en prosa y verso del cura de Fruíme D. Diego Antonio Cernadas y Castro, Tomo II. Madrid: Joachin Ibarra, 1778

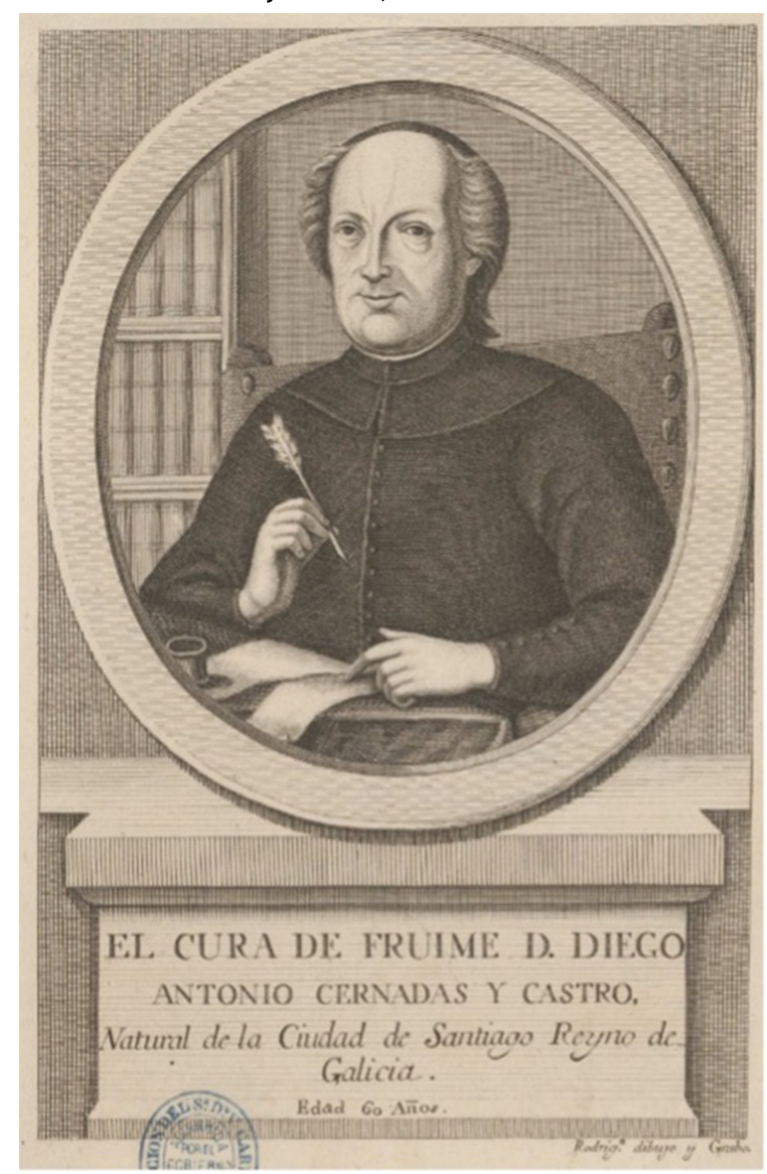

Pese a todo, aunque la Carta-Quenta del cura de Fruíme es obra suficientemente conocida que suele citarse por aquellos autores que han estudiado la obra de Cernadas o la historia de la fiesta en la Galicia moderna ${ }^{11}$, es indudable que, en el aspecto que a nosotros interesa, tiene todavía ciertos campos de interés sin explorar; de ahí que hayamos considerado volver a recuperar partes del texto del famoso sacerdote, centrándolo esta vez en aquellos momentos que más se detienen en la descripción de la ciudad Santiago, sus plazas, calles o principales monumentos, lo que nos proporciona una visión de Compostela en 1759 ciertamente interesante.

Aunque no es exactamente igual, pues no llega a ser tan abundante en datos y referencias, ni tampoco tiene la misma intención, en cierto modo podría decirse que el comentario de Cernadas puede ponerse en relación con el escrito publicado en 1731 por Pablo Mendoza de los Ríos, en su Theatro moral y político de la noble Academia Compostelana; si bien éste recreando una ficticia visita de un peregrino a la ciudad de Santiago y el del cura de Fruíme, en cambio, aprovechando un momento de aclamación pública de un rey, como era el caso de Carlos III.

Desconocemos quién procedió a elegir a Cernadas como relator del festejo, aunque es probable que, dadas las buenas relaciones que nuestro sacerdote tenía con las mejores familias de la ciudad, la elección saliese de algún miembro distinguido de la Corporación ${ }^{12}$, que consideró al famoso cura de Fruíme la persona adecuada para darle forma de una manera vivaz, personal y erudita. Fue sin duda un acierto. De hecho la Carta-Quenta va más allá de lo que suele ser un mero relato festivo 
sin más, pues se trata en realidad de un compendio de muchas cosas que ponen de manifiesto la importante cultura del conocido clérigo santiagués, su gran capacidad para versificar con gracejo e ironía pero, sobre todo, de sacar a la luz también, en casi cualquier circunstancia, los temas que en él fueron casi siempre una cuestión de principios: por una parte, la defensa de Galicia y los gallegos frente al menosprecio de las gentes del exterior, la valoración de la lengua gallega que también estaba arrinconada en los medios castellanos y, ya puestos, también su posición en las "guerras" internas que existían entre las ciudades de A Coruña y Santiago por ser consideradas ambas "cabeza del reino", bien por ser la primera la ciudad en donde residía el capitán general y la Real Audiencia, y la segunda, en cambio, por ser la "más antigua", prestigiosa y poblada de Galicia. En este tema, sin embargo, no había dudas para el cura de Fruíme, que opta obviamente por su ciudad natal, ya que en su relato de los festejos lo deja muy claramente expuesto: "Bien sé que la Coruña alega su derecho à este Titulo, por ser residencia de el Señor Capitan General,...; pero Santiago, lo es por antonomasia, y porque aquí tiene su Solio el Generalissimo de las Armas Españolas”, claro está en evidente alusión al Santiago Caballero protector de la nación.

Por último, merece destacarse que los ejemplares que regalaron al autor -así lo indica en la portada- los dedicó a su gran amigo Vicente Móñez y Gómez, capitán de caballos y ayudante del mando militar de la Corte y Reales Sitios, residente en Madrid, a quien Cernadas había conocido mucho antes y con quien compartió una gran devoción por la virgen de los Dolores que se encontraba en la iglesia de Fruíme. Móñez había adornado con un donativo la capilla de la Dolorosa y desde entonces surgió entre párroco y donante una amistad que duraría hasta la muerte del famoso cura santiagués, en 1777. De hecho, Móñez fue uno de los que más contribuyeron a que, tras la muerte de Cenadas, su obra no se perdiese y saliese compilada a la luz, en siete volúmenes, que iniciaron su publicación en $1778^{13}$.

En cualquier caso, más allá de que Cernadas describa los días de fiesta centrándose inicialmente en lo llamativo de las iluminaciones nocturnas que llegaron a encender más de "dos mil hachas", especialmente brillantes en la fachada del Concejo situado en la plaza del Campo y en los edificios que presidían la plaza de Azabachería (que llegó a parecer, según él, un “jardín poblado de flores de mano, color de fuego"), Cernadas se centra de manera muy especial en comentar el gran festejo nocturno celebrado el día 13 de octubre, víspera del alzamiento de pendones, en el que, junto a un preciso itinerario que va marcando las pautas de lo que era, en efecto, un acontecimiento civil que competía al Concejo, describe también lo aparatoso de la carroza que había pagado, por cierto, el gremio de los plateros. Así, del itinerario dice que la gran cabalgata salió de la plaza del Consistorio -hoy de Cervantes-, bajó por la calle de Azabachería hasta la plaza del palacio arzobispal y el monasterio de San Martín para, después de pasar bajo el arco de palacio, desembarcar en la plaza del Hospital donde se paró brevemente ante la fachada de la Catedral, poco antes de seguir rumbo a la plaza de Platerías, rúa del Villar, plaza del Toral, rúa Nueva, plaza de la Quintana, plaza de Feijóo, Preguntoiro y, finalmente, culminar de nuevo en la plaza del Campo donde remató todo el recorrido triunfal.

También describe, como hemos dicho, de manera muy precisa la gran carroza que, tirada por cuatro yuntas de poderosos "brutos" enmascarados como si fuesen los cuatro evangelistas con rostros de Hombre, León, Águila y Buey - "idea de los Cielos, para hacer memorable una Carroza”, dice el autor-, "llevaba en su solio el retrato pintado del monarca y, a sus lados, las "estatuas vivas" de la que llama Cernadas "Real Familia", entre los que menciona a la reina consorte María Amelia 
[sic], a la reina madre Isabel de Farnesio y a sus hijos la reina de Portugal, la duquesa de Saboya, el duque de Parma y el infante don Luís; es decir, Mariana Victoria, María Antonia, Felipe y Luís.

Es llamativo comprobar que esta familia real en realidad hace alusión a los principales descendientes de la reina madre, así considerada como la gran matriarca borbónica, antes que a la familia principal del nuevo rey cuyos hijos, por ejemplo, no aparecen. Quizá eso explique que Cernadas se explaye en comentar, a la hora de precisar más el aspecto que presentaba la carroza, que el "respaldo de el assiento de la Señora Reyna Madre era un frondoso Laurel, de que salian otras tantas ramas, como son sus Augustos Hijos, y formandose de éllas unos arcos, les servían de Coronas". En todo caso, el carro iba iluminado con bujías y vistosas arañas, llevaba también una orquesta de músicos y voces que iban interpretando sonatas y letrillas y, en lo que podríamos denominar proa del carro triunfal, dos leones rampantes que llevaban en sus garras dos globos, en referencia sin duda a ambos mundos en los que era señor el nuevo soberano. Sobre ellos, finalmente, un vítor con el nombre del rey que culminaba la carroza. Se entiende, pues, que Cernadas aludiese al carro triunfal como si fuese "una abreviatura de la Esfera, pues en ella estaban colocados siete planetas tan brillantes", claro está en relación con los siete personajes reales que llevaba sobre ella ${ }^{14}$.

Por otra parte, la marcha de la comitiva es aprovechada por el cura de Fruíme para ir resaltando construcciones importantes de la ciudad. Entre ellas el Consistorio, de donde partió la cabalgata, que presentaba casi el mismo aspecto del edificio que todavía existe en la plaza de Cervantes y que había trazado Domingo de Andrade en 1689, si bien junto a su largo balcón, disponía también entonces, en sus dos fachadas, vistosas gárgolas y sendos escudos Real y de la Ciudad que hoy han desaparecido $^{15}$.

Ya en la plaza de Azabachería ${ }^{16}$, que entonces debía presentar la fachada de la catedral toda cubierta de andamios por motivo de las obras de sustitución de la vieja fachada románica por la barroca que proyectó Lucas Ferro Caaveiro y reformó Ventura Rodríguez ${ }^{17}$, destaca Cernadas, de manera muy especial, el lustre del frente del palacio arzobispal que no coincidía tampoco con el que existe actualmente. De hecho, el palacio original estaba más adelantado sobre la plaza y tenía el aspecto de un noble caserón renacentista que, tal como se ve en viejos dibujos y grabados decimonónicos, poseía una puerta principal ricamente flanqueada con dos figuras de atlantes que eran, en sí mismas, bastante excepcionales en la arquitectura compostelana ${ }^{18}$. Señala asimismo nuestro autor la vieja fuente de San Juan que, para entonces, después de las grandes transformaciones urbanas que había vivido la plaza como resultado de las obras llevadas a cabo por la abadía de San Martín, todavía presidía uno de los sectores más cercanos a la rúa da Moeda Vella, aunque ya por entonces estaba la fuente sin la escultura del Apóstol que le había dado nombre ${ }^{19}$. Finalmente, Cernadas llama la atención sobre la "magnífica, dilatada y sumptuosísima" fachada que daba forma al monasterio benedictino ${ }^{20}$, entonces ya presidida con la suntuosa escalinata diseñada por Fray Manuel de los Mártires ${ }^{21}$; y no conforme con alabarla con el nombre de "casa real", acaso por ser fundación regia y tener en la portada el escudo real, hace que, al paso de la gran procesión, interactúen con el áulico cortejo algunas de sus esculturas; entre ellas la del San Martín a caballo que preside la peineta que, dice, tuvo que quedarse "allí quietecito, como un Santo" para no entrar en acción y participar en la comitiva, o el cuervo de la estatua de San Benito de la hornacina que se quedó tan boquiabierto, vuelve a indicar, que "por poco no se le cayó el panecillo, en que se ve el milagro de estar la piedra convertida en pan". 
Curiosamente, es escueto al comentar la "espaciosíssima" plaza del Hospital, entonces todavía sin la poderosa mole del Palacio de Rajoy -recuérdese que se inició en 1767-, pues ni menciona el Hospital Real que le daba nombre, ni el Colegio de San Jerónimo ${ }^{22}$, ni la fachada renovada del claustro capitular ${ }^{23}$ y solo alude muy de pasada a la gran fachada del Obradoiro que apenas se había culminado hacía una década, en 1750, un año después de la muerte de su autor Fernando de Casas $^{24}$. Es de suponer que Cernadas admiraría esta obra, pues en parte coincide en lo artístico con su manera barroca de versificar. Por el contrario, solo da de ella una brevísima alusión, cuando interactuando esta vez con el dedicando -Vicente Móñez y Gómez-, dice en el texto "no tema Vmd. que se la pinte aquí, porque es mucha obra".

Tras la parada en la plaza, siguió el cortejo hacia Platerías donde niega el autor la descripción de la catedral y el frente claustral del Tesoro, no menciona tampoco la gran fachada de la Casa del Cabildo -concluida precisamente un año antes, en 1758, para ornato público de la ciudad por el arquitecto Clemente Fernández Sarela- ${ }^{25}$ o el cierre de casas que precedieron al que luego fue el Banco de España y hoy es Museo de las Peregrinaciones, y pone la atención, por el contrario, en destacar la actividad de los plateros que habían pagado la carroza, y en ponderar la fuente que presidía la plaza y que, insiste nuestro cura en afirmar, "es una de las mas hermosas, y magnificas alhajas de la Ciudad" y que estaba culminada por "su buena estrella" en alusión, obviamente, a la figura del astro de ocho rayos que la coronaba y de los que brotaba otros tantos hilillos de agua.

Ha de tenerse en cuenta, no obstante, que la fuente que se comenta no es la actual que preside la plaza, obra del siglo XIX, sino la levantada por Domingo de Andrade en $1705^{26}$ y que, por cierto, había descrito con brillantez Antonio Riobóo y Seixas, el gran rival de nuestro cura y con el que tuvo Cernadas cierta tirantez ${ }^{27}$. Sea como fuere, desde aquí prosigue el de Fruíme la descripción del cortejo, primero en su recorrido por la rúa del Villar y luego en su desembarco en la plaza del Toral a la que llama "jarifa" bien por su ajetreo de tipo popular o por las bellas arquitecturas que la definían.

No tenía entonces la plaza la fuente que hoy la preside, aunque estaba en mente del Concejo construirla por considerar que tendría mucha utilidad ${ }^{28}$; en cambio, centra la atención Cernadas en ponderar en todos sus valores monumentales la moderna fachada del Palacio de Bendaña, atribuida a Clemente Fernández Sarela y de hacia la mitad de la década de $1740^{29}$, de la que dice "puede llamarse la Fenix de todas las de la Ciudad" pues renació de las cenizas tras un incendio y era en su rebrote "sin duda la mas linda, y mas lustrosa" de toda Compostela. Había sido levantada, al parecer por D. Andrés Vicente Piñeyro y Ulloa, tercer marqués de Bendaña que, justo en 1759, acababa de solicitar a la Ciudad permiso para ampliar su palacio con un cenador y galería que daban a la rúa Nueva "para el lucimiento de la Ciudad y desahogo de su Casa" ${ }^{30}$. Estaba por lo tanto en todo su esplendor.

En el Toral, vuelve de nuevo el autor a fijarse en las estatuas acróteras que culminaban los edificios buscando que dialogasen, como si fueran figuras vivientes, con las reales que formaban parte del cortejo. Y en este caso llama la atención sobre el "Hércules" que, según él, coronaba el palacio del marqués sosteniendo la bola del mundo, aunque hoy se cree, más bien, que sea en realidad un Atlas en la misma actitud ${ }^{31}$, pues no lleva, como atributo, la piel de león que suele caracterizar al mítico héroe tebano. Y dice así nuestro autor: "quando llegó alli el triumphal aparato, me pareció, que la Estatua [de Hércules], que, agoviada con el peso de la machina rotunda, tiene inclinada la Cabeza, la bajaba mucho mas, como, haciendo cortesia à los Retratos de nuestros Reyes, en ademán de querer sacudir, y arrojar à sus Reales pies toda la Esfera, y reconocerlos de parte de 
los Dueños de la Casa por Señores de dos Mundos. Yo à lo menos assi lo imaginé, y estoy cierto de que no me engaño en el significado de el Símbolo".

En esta plaza también comenta, aunque de pasada, la presencia de la casa inmediata al palacio de Bendaña que dice "hace machado" con ella y en donde estaba la Administración de las Rentas Provinciales que, por cierto, todavía seguía allí a mediados del siglo XIX tal como relatan ciertas obras de ese tiempo ${ }^{32}$. Con todo, pasado este punto, el recorrido prosiguió por la rúa Nueva hasta desembocar en la plaza de la Quintana.

De la primera se explaya Cernadas refiriéndonos que era "grande, y distinguida" y que "toda élla no cede à otra alguna en la hermosura de sus Casas, y la Nobleza de sus Habitadores, antes en esto es mas seguidamente llena de gente de cathegoria, pues, con ser la Calle mas larga de la Ciudad, son bien raras las Casas, que no sean de Personas de primer linea; por aqui podrá Vmd. inferir, que bizarra, y que flamante estaría la Carrera?". Y respecto a la Quintana, en donde transcurrió un momento capital del festejo, cita muchas otras cosas de interés: la espectacularidad de sus muchas luminarias que resplandecía con inusitado fulgor, en especial sobre la fachada del monasterio de San Pelayo que, al estar todas sus ventanas tiradas "à cordel, no parecía, sinó que alli se havia pintado en aquel lienzo una Procession de la Candelaria"33; también la llanura de la plaza, la Torre del Reloj, reformada por Domingo de Andrade ${ }^{34}$, cuyo artilugio horario contribuyó a la fiesta al dar, justo en el momento en que pasaba el cortejo, los "dos cuartos" para celebrarlo. Cita asimismo la Puerta Santa que, dice, quedó sorprendida por tanto gentío y casi se sale de sus quicios pensando que era víspera de Año Santo; en fin, que no deja de exaltar Cernadas la brillantez de la fiesta volviendo a hacer interactuar a otra de las estatuas acróteras, pues vuelve a decir que la escultura ecuestre del Santiago Caballero que presidía el Pórtico Real - se refiere a la estatua que entonces lo coronaba, obra del escultor Diego Fernández de Sande y de $1725^{35}$ - estaba "como que passaba la revista" en su condición de "Generalissimo de las Armas de España” lo que infundía obviamente una gran "veneracion, y respeto".

De allí la cabalgata real se trasladó a la plaza de Feijóo que, señala Cernadas, también se llamaba de "la Hierva: porque en élla se vende el forrage para todo el ganado de el Lugar" ${ }^{36}$. Indica a su vez que era "pequeña, pero agraciada por los bellos Edificios, que la circundan" ${ }^{37}$, destacando entre ellos "la Casa de el Regidor Decano, à quien tocaba en el siguiente dia levantar el Real Estandarte, llamado D. Joseph Antonio Somoza, y Ossorio, que es un Caballero de una noble calidad, y condición, venerable, apacible, y pundonoroso". Comenta la belleza con que estaban engalanados e iluminados sus balcones, pues se había encargado de ellos "su Mujer, que es una Matrona de alta jerarquía... Decana de las Señoras del Lugar". Ha de referirse, ciertamente, al gran caserón barroco que sigue presidiendo la plaza y que está configurado en el estilo de Andrade. En todo caso, es aquí donde aprovecha el autor para hacer su proclamación pública de galleguismo indicando que allí se había cantado "(atendiendo à las circunstancias de el sitio) la siguiente Letrilla en el dialecto Gallego, porque como era natural, era el proprio":

\author{
Diz que xá ven por camiño \\ ò noso Rey, Dios ò traya, \\ porque, segun nos din todos, \\ hé lindo, como una prata, \\ Talalála, talaléla \\ Talalíla, talalála...
}


Dice al respecto el ilustre cura santiagués, en defensa del gallego, que era lo justo "porque los Reyes, que son en la tierra los mas vivos retratos de Dios, deben ser, en su proporción, alabados, como el todo Poderoso, y à éste le magnifican no solo todos los Pueblos, Tribus, y Naciones, sinó tambien todas las Lenguas, y no era razon, que los Gallegos no la tuviesen para ensalzar à su Señor, y que los Castellanos no los dejen hablar con la lengua, que Dios les dio".

Finalmente, el cortejo concluyó en la plaza del Consistorio de donde había salido, sin indicar Cernadas ninguna cuestión especial; solo la mención de algunos de los caballeros más renombrados que formaban parte de la real procesión, entre los que cita, además de a Joseph Antonio Somoza ya señalado, a Juan Antonio Cisneros y al conde de Priegue personajes los dos muy notorios y públicos entre la ciudadanía compostelana.

Al día siguiente, 14 de octubre, tuvo lugar realmente la proclamación oficial del monarca con alzamientos de pendones en los tres escenarios que se habían montado para el efecto. El itinerario del cortejo fue el mismo del día anterior, también parte de la comitiva, aunque esta vez no participó la carroza; así que, junto a los ochenta jinetes con sus volantes que abrían el cortejo y los reyes de armas, maceros, pífanos y demás, el gran protagonista era, esta vez, el portador del estandarte que era llevado con gran gallardía por el regidor más antiguo del Concejo, el ya mencionado Joseph Antonio Somoza. Hubo escenarios en la plaza de Palacio, en la Azabachería, donde se tremoló el pendón, se dieron vivas a Carlos III y se tiraron monedas de plata al público que estaba reunido en la plaza $^{38}$, todo ante la presencia del arzobispo Bartolomé Rajoy que había abandonado su retiro de Lestrove para participar personalmente en el acto. El segundo escenario tuvo lugar en la plaza de Feijóo, donde los actos solemnes se repitieron, del mismo modo que en el tercer tablado de la plaza del Consistorio que, como peculiaridad, tenía a mayores en el estrado real el retrato del rey "en quadro" bajo riquísimo dosel, acaso el mismo que había presidido la carroza y se había pintado de manera apresurada ${ }^{39}$.

Nada nos cuentan ni las actas municipales ni el autor del comentario sobre la calidad del retrato ni su autoría; pero debió ser un simulacro del rey con más apariencia que calidad y lo más probable es que hubiese sido realizado, con la urgencia de la ocasión, por el "maestro pincelista" de la ciudad, que no era otro que Manuel Landeira y Bolaño desde $1756^{40}$. El retrato oficial del monarca, de cuerpo entero, que después presidió la sala de reuniones del Ayuntamiento fue encargado a Madrid el 1 de enero de 1760, pasados ya estos hechos, y realizado por Andrés de la Calleja Robredo (1705-1785), pintor de Cámara y Académico de Bellas Artes de San Fernando ${ }^{41}$. De este modo, el citado día, el consistorio hacía el encargo a su agente en la Corte, Manuel de Grandal y Neira ${ }^{42}$, respondiendo éste el 23 de enero para comunicar que ya lo había encargado a "Don Andrés Callejo [sic], pintor de Cámara de S.M., que me hizo el de la Ciudad de Lugo" ${ }^{\prime 3}$. El retrato del monarca realizado por Andrés de la Calleja ya se encontraba en la Sala de reuniones de la Corporación Compostelana el 1 de enero de $1761^{44}$, aunque actualmente ya no se conserva. Podemos conocer, no obstante, cómo sería pues sí conservamos el realizado para la Corporación lucense unos meses antes, en el último cuatrimestre de 1759 (fig.2) ${ }^{45}$. 
Fig. 2. Calleja Robredo, Andrés de la: Retrato de Carlos III, 1759. Óleo, Salón de Plenos del Concello de Lugo

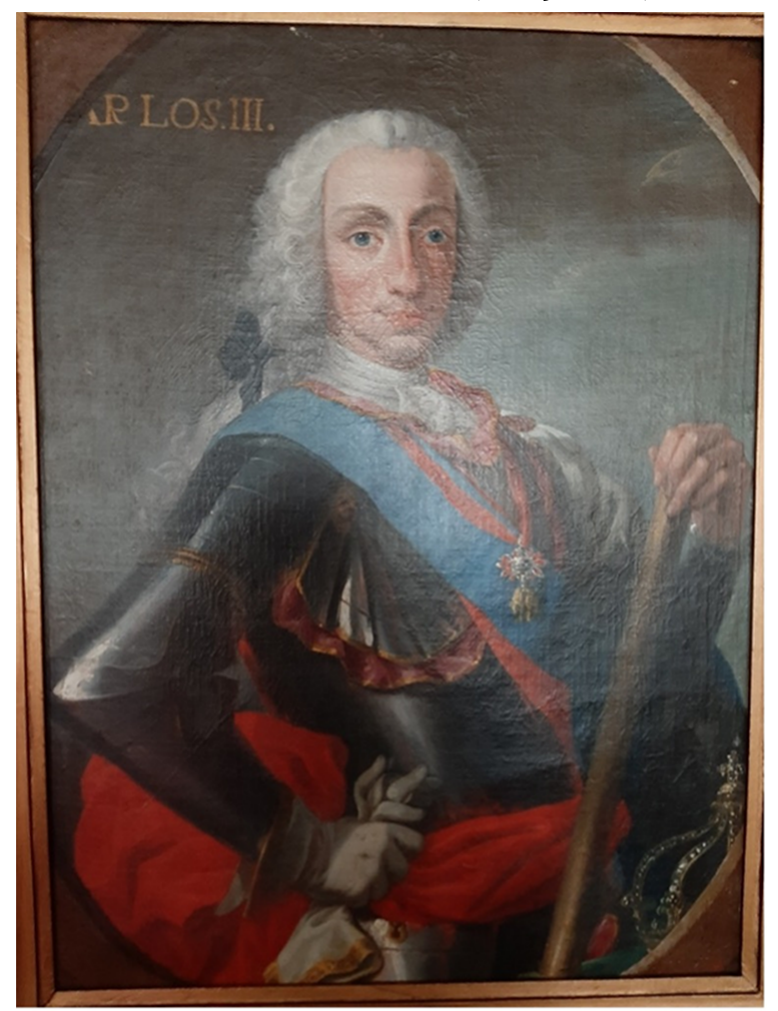

Es un interesante retrato del joven monarca dispuesto con señorial apostura, larga peluca empolvada recogida con lazo, el collar del Toisón, armadura, guantes y la bengala de general en la mano, hoy en un amplio medio plano -parece no obstante recortado, pues se ven incompletos y encerrados en un óvalo el nombre de Carlos III y la corona real-, en la tradición del barroco tardío de la escuela madrileña, influenciado por la factura elegante de los retratos cortesanos de LouisMichele Van Loo pero ajeno aún al influjo de Antonio Raphael Mengs (que llegó a España en 1761). El retrato, que hasta este momento se consideraba anónimo, se encuentra aún en nuestros días en el Salón de Plenos del Ayuntamiento de Lugo.

En todo caso, volviendo a los actos festivos, tras los últimos vivas al rey en donde también se mencionó, muy alto, el nombre de Galicia por tres veces, los actos del día concluyeron colocando el pendón real en el balcón del Consistorio donde quedó expuesto bajo dosel ante la vista del público. Solo quedó después un nuevo día de fiesta que esta vez se limitó, a las ya mencionadas luminarias, fuegos artificiales y repique universal de campanas con lo que se puso punto final, luminoso y muy sonoro, a la proclamación del monarca, con la única "diferencia de que la Fuente de la Plaza de las Casas Consistoriales, estuvo adornada con varios arcos, y coronacion de fuegos, que remataba con un Victor de el Rey, Nuestro Señor, iluminado, que duró assi desde poco despues de anochecer hasta casi las diez".

\section{REFERENCIAS}

Beiras García, Eduardo. Lucas Ferro Caaveiro e a cidade de Santiago de Compostela. A Coruña: Fundación Caixa Galicia, 2008. 
Beiras García, Eduardo. El arte del agua. Compostela y sus fuentes públicas monumentales de la Edad Media al siglo XX. Santiago de Compostela: InÉditor, 2012.

Bonet Correa, Antonio. La arquitectura en Galicia en el siglo XVII. Madrid: Consejo Superior de Investigaciones Científicas, 1966.

Cebreiros Álvarez, Eduardo. El Municipio de Santiago de Compostela a finales del Antiguo Régimen (1759-1812). Santiago de Compostela: Escola Galega de Administración Pública, 1999.

Cernadas de Castro, Diego Antonio. Carta-quenta, ó razón en suma de las festivas gozosas demostraciones, con que la muy Noble, y muy Leal Ciudad de Santiago de Galicia celebró la Solemne Aclamación de Nuestro Rey, y Señor Don Carlos III. Santiago de Compostela: Andrés Frayz, [1760].

Cernadas de Castro, Diego Antonio. Voces métricas de la M.Ny M.L. ciudad de Santiago, en la proclamación de N. Rey y Señor D. Carlos Tercero. Madrid: Andrés Ortega, 1760.

Cernadas de Castro, Diego Antonio. “Carta-Cuenta, ó razón en suma de las festivas gozosas demostraciones, con que la muy Noble, y muy Leal Ciudad de Santiago de Galicia celebró la solemne Aclamación de nuestro Rey y Señor Don Carlos III." En Obras en prosa y verso del Cura de Fruíme D. Diego Antonio Cernadas y Castro, natural de Santiago de Galicia, Tomo V, 136-199. Madrid: Joachin Ibarra, 1780.

Cernadas, Diego Antonio de. “Festas na cidade de Santiago co gallo da aclamación de Carlos III," En Xornalistas con opinión II. Escolma de textos, ed. Rosa Aneiros Díaz, Xosé López García y Víctor F. Freixanes, 12-16. Santiago de Compostela: Consello da Cultura Galega-Editorial Galaxia, 2010.

Couselo Bouzas, José. Galicia artística en el siglo XVIII y primer tercio del siglo XIX. Santiago de Compostela: Imprenta del Seminario, 1932.

Fernández Sánchez, José María y Francisco Freire Barreiro. Santiago, Jerusalén, Roma. Santiago de Compostela: Imprenta del Boletín Eclesiástico, 1881.

Folgar de la Calle, Mạ del Carmen. Arquitectura gallega del siglo XVIII. Los Sarela. Santiago de Compostela: Universidad de Santiago, 1985.

García Cortés, Carlos. O cura de Fruíme. Diego Antonio Cernadas e Castro (1702-1777). Santiago de Compostela: Instituto Teolóxico Compostelano, 2002.

López, Roberto J. "La financiación de las ceremonias públicas en el noroeste de España en el siglo XVIII," Espacio, tiempo y forma, Serie IV, 7 (1994): 367-382.

López, Roberto J. Ceremonia y poder a finales del Antiguo Régimen. Galicia 1700-1833. Santiago de Compostela: Universidad de Santiago de Compostela, 1995.

Martín García, Ana. "La Puerta de los Carros del monasterio de San Payo de Antealtares. Arquitectura, poder y urbanismo," Cuadernos de Estudios Gallegos, XLVII, 112 (2000): 249-288.

Mendoza de los Ríos, Pablo. Theatro moral, y politico de la noble Academia Compostelana. Santiago: [s.n.], 1731.

Morales Piga, María Luisa. “Andrés de la Calleja." Tesis doctoral, Universidad Complutense de Madrid, 1993.

Murguía, Manuel. El arte en Santiago durante el siglo XVIII y noticia de los artistas que florecieron en dicha ciudad y centuria. Madrid: Establecimiento tipográfico de Ricardo Fé, 1884.

Pérez Costanti, Pablo. “Las Casas Consistoriales de Santiago," En Notas viejas galicianas, 287-292. Santiago de Compostela: Xunta de Galicia, 1993.

Pérez Costanti, Pablo. "El Toral. Historia de una fuente," En Notas viejas galicianas, 421-422. Santiago de Compostela: Xunta de Galicia, 1993.

Pita Galán, Paula. Fray Manuel de los Mártires, maestro de obras de San Domingos de Bonaval. Santiago de Compostela: Consorcio de Santiago, 2017. 
Rey Castelao, Ofelia. "Producción impresa y promoción eclesiástica en la Galicia de fines del Antiguo Régimen," Semata, 10 (1998): 281-319.

Rivas Troitiño, José Manuel. “D. Diego Antonio Zernadas, un periodista gallego en el siglo XVIII.” Estudio sobre el mensaje periodístico, 4 (1998): 161-189.

Rosende Valdés, Andrés. Unha historia urbana: Compostela 1595-1780. Santiago de Compostela: Nigra Trea, 2004.

Sambricio, Carlos. "Fiestas en Madrid durante el reinado de Carlos III," En Carlos III, Alcalde de Madrid, 575-629. Madrid: Ayuntamiento de Madrid, 1988.

Tamayo, Juan Antonio. "Madrid por Carlos III. Fiestas reales en la villa y corte." Revista de la Biblioteca, Archivo y Museo, 2 (1944): 293-368.

Taín Guzmán, Miguel. Domingo de Andrade, maestro de obras de la catedral de Santiago (1639-1712). Sada: Ediciós do Castro, 1998.

Taín Guzmán, Miguel. La Casa del Cabildo de Santiago de Compostela (1745-1759): "pro commoditate ac ornato urbis". Madrid-Santiago: Electa-Consorcio de Santiago, 2000.

Taín Guzmán, Miguel. As antigas Casas do Concello de Santiago de Compostela. Santiago de Compostela: Concello de Santiago-Universidade de Santiago, 2003.

Taín Guzmán, Miguel. "La Casona de la Azabachería del Palacio Arzobispal (Santiago de Compostela)." En Arquitecturas desvanecidas. Memoria gráfica del Patrimonio desaparecido en Galicia, editado por Jesús Ángel Sánchez García, Julio Vázquez Castro y Alfredo Vigo Trasancos, 293-298. Madrid: Abada, 2019.

Vázquez Castro, Julio. “La Berenguela y la Torre del Reloj de la catedral de Santiago." Semata, 10 (1998): 111-148.

Vigo Trasancos, Alfredo. La fachada del Obradoiro de la catedral de Santiago. Madrid: Electa-Consorcio de Santiago, 1996.

Vigo Trasancos, Alfredo. La catedral de Santiago y la Ilustración. Proyecto clásico y memoria histórica (1757-1808). Madrid: Electa-Consorcio de Santiago, 1999.

Vigo Trasancos, Alfredo. "Esplendor barroco y orden académico (1643-1807). Arquitectura, metáfora y magnificencia." En La catedral de los caminos. Estudios sobre arte e historia, editado por Ramón Yzquierdo Peiró, 555-653. Santiago: Fundación Catedral de Santiago, 2020.

Yzquierdo Peiró, Ramón. La Berenguela. Santiago de Compostela: Teófilo-Consorcio de Santiago, 2012.

Notas

1 La realización de este estudio se inscribe en el marco del proyecto “Memoria, textos e imágenes. La recuperación del patrimonio perdido para la sociedad de Galicia" (PID2019-105009GB-I00) y ha contado con el apoyo del Ministerio de Ciencia e Innovación. Asimismo se ha beneficiado de la ayuda del Programa de Consolidación e Estruturación de Unidades de Investigación Competitivas do SUG. Modalidade: Grupos con Potencial de Crecemento. Nºxpediente: ED431B 2020/41.

2 Arquivo Histórico da Universidad de Santiago (AHUS), Archivo Municipal de Santiago (A.M.), Libro de Actas 206, f. 22v-24r. Para otros actos de proclamación en el resto de España, especialmente en Madrid, véase Tamayo, "Madrid por Carlos III" y Sambricio, "Fiestas en Madrid"; para su contexto en las celebraciones gallegas puede verse López, Ceremonia y poder. Sobre el municipio de Compostela en esa época véase Cebreiros, El Municipio de Santiago.

3 AHUS, A.M. 206, f. 22v-24r.

4 AHUS, A.M. 206, f. 70r-v, 83r, 90v, 91r y 94v.

5 Sobre el préstamo véase AHUS, A.M. 206, f. 22v-24r, 32r-33r, 34r, 70r-v, 124v y 138v; A.M. 207 , f. 56v-57r y A.M. 209, f. 86r -donde se satisface el citado préstamo y su interés, que sumaron ambos 38.520 reales-.

6 AHUS, A.M. 206, f. 22v-24r, 70v-71r y 90v-91r. 
AHUS, A.M. 206, f. 104r.

El 18 de marzo de 1760 se mandó "ymprimir la Real funzion de Aclamacion echa en esta ciudad" por el rey Carlos III (AHUS, A.M. 207, f. 253v) y el 19 de julio de dicho año se pagaron 885 reales y 2 maravedís por los 600 ejemplares realizados por el impresor Andrés Frayz y 300 reales al librero Cayetano Vázquez por encuadernarlos (AHUS, A.M. 208, f. 144r-145r).

AHUS, A.M. 208, f. 144r-145r.

Algunos fragmentos poéticos fueron impresos en Madrid, sin el permiso del autor, con el título de "Voces métricas de la M.N y M.L. ciudad de Santiago, en la proclamación de N. Rey y Señor D. Carlos Tercero" por Andrés Ortega en 1760, lo que motivó una querella de Cernadas al Marqués de Estepa, presidente de la Academia Poética Matritense (Tamayo, "Madrid por Carlos III," 308; Cernadas, "Obras en prosa y verso," V, 281-288 y Rivas, "D. Diego Antonio Zernadas," 169).

López, "La financiación de las ceremonias," 375; López, Ceremonia y poder, 148-149; Rey, "Producción impresa," 295; Rivas, "D. Diego Antonio Zernadas," 167 o García, O cura de Fruíme, 157-159 y 236. Un breve resumen de la Carta-Quenta fue publicado en Cernadas, "Festas na cidade de Santiago," 12-16.

Es posible que fuese el Regidor Decano, don José Antonio Somoza y Ossorio, dados los efusivos elogios que recibe en la Carta-Quenta tanto él como su esposa.

Rivas, “D. Diego Antonio Zernadas," 163 y García, O cura de Fruíme, 109.

El 9 de octubre, el señor Juan Ramírez, como encargado de la máscara, expone al acuerdo cómo se iba a desarrollar: "un Carro triunfante, en que ba puesto dicho señor Rey don Carlos tercero en retrato, las Reinas nuestra señora reinante y viuda, la de Portogal, la señora ynfanta de Zerdeña, los señores ynfantes don Phelipe y don Luis, formando un arbol geanolojico de la descendencia Real de España que vaia, con su musica presidiendo por su orden los quatro consejos de Castilla, Guerra, Hacienda y Ordenes con sus distintiuo cada uno, sus alauarderos, las siete Virtudes, las tres Potencias; dos Reies de Armas con sus escuderos delante, quatro ninfas y un angel en medio con un Vitor de la reina nuestra señora por que el del Rey nuestro señor ya ba en el Carro, y otras diferentes parejas que adornan la funcion" (AHUS, A.M. 206, f. 90v-91r). Sin embargo, unos días después, el 12 de octubre, el día antes del acto, tras un acalorado debate, se decide que la representación de los cuatro reales Consejos "se muden y pongan otros" por ser "una accion nada decorosa ni al honor de la Ciudad ni a la eleuada representacion de tan Superior tribunal" (AHUS, A.M. 206, f. 95r-96v).

Pérez, "Las Casas Consistoriales," 287-292 y Taín, As antigas Casas do Concello, 28, 37 y 63-67.

Para la configuración de esta plaza en este momento véase Rosende, Unha historia urbana, 318-371.

Vigo, La catedral de Santiago, 54-55.

Rosende, Unha historia urbana, 324 y Taín, "La Casona de la Azabachería”.

Rosende, Unha historia urbana, 319 y 337-338 y Beiras, El arte del agua, 69-70.

Bonet, La arquitectura en Galicia, 476-490.

Pita, Fray Manuel de los Mártires, 77.

Sobre la configuración de esta plaza en este momento véase Rosende, Unha historia urbana, 261-317.

Se había reformado entre 1751 y 1756 por Lucas Ferro Caaveiro, tras el incendio que tuvo lugar en 1751. Véase Beiras, Lucas Ferro Caaveiro, 58.

Vigo, La fachada del Obradoiro, 99.

Para la configuración de esta plaza, en este momento, véase Rosende, Unha historia urbana, 233-260. Sobre la casa puede consultarse Folgar, Arquitectura gallega, 102-115 y Taín, La Casa del Cabildo.

Taín, Domingo de Andrade, I, 347-349; Rosende, Unha historia urbana, 255-256 y Beiras, El arte del agua, 113. García, 0 cura de Fruíme, 222-232.

AHUS, A.M. 201, f. 82r-83v y f. 293r-v. No obstante, no se construiría hasta 1820 (Pérez, "El Toral," 422). Folgar, Arquitectura gallega, $65-66$.

AHUS, A.M. 205, f. 65 v y f. 92r-v.

Folgar, Arquitectura gallega, 69.

Fernández, Santiago, Jerusalén, Roma, I, letra g del plano situado entre las páginas 8 y 9.

Para esta fachada y, en general, la configuración de esta plaza en ese momento, véase Rosende, Unha historia urbana, $190-232$.

Sobre cómo era la torre antes y después de la intervención andradina véase Vázquez, "La Berenguela," 111-148; Bonet, La arquitectura en Galicia, 377-384; Taín, Domingo de Andrade, 112-128; Yzquierdo, La Berenguela y Vigo, “Esplendor barroco," 588-592. 
Couselo, Galicia artística, 308 y Taín, Domingo de Andrade, I, 161.

El consistorio había intentado, sin éxito, trasladar el comercio de hierba a la plaza del Mercado en ese mismo año, 1759, pues "los hazes de paja y de hierba... ocupaban el paso en la plazuela de Feixó... causando graves inconbenientes, y aun a peligro a subceder muertes con tanta concurrencia de cavallerías, carros cargados y concurso de gentes" (Martín, "La puerta de los Carros," 273-274).

Uno de ellos sería la "Puerta de los Carros" del Monasterio de San Paio de Antealtares, concluida en 1749 pero dotada con un hermoso mirador en los primeros años del siguiente decenio (Martín, "La puerta de los Carros," 284).

8 Era costumbre, al parecer, el arrojar al público monedas de oro o plata en los actos de proclamación de los reyes. Véase Tamayo, "Madrid por Carlos III," 297.

La reseña detallada de esta celebración, con el tono preciso y prosaico de un acta notarial, se encuentra en AHUS, A.M. 206, f. 98r-100v.

AHUS, A.M 198, f. 355r-v. Sobre Manuel Landeira véase Murguía, El arte en Santiago, 49-51 y 218 y Couselo, Galicia artística, 406-407. Manuel Murguía sugiere que Miguel Varela habría pintado el carro triunfal y algunas otras figuras alegóricas por la cantidad de 2.600 reales, si bien da la extraña fecha de 1770 pese a citar expresamente que todo se había pintado para la coronación de Carlos III (Murguía, El arte en Santiago, 232). Couselo Bouzas atribuye al citado Miguel Varela la pintura, dorado y estofado del arca que sirvió para llevar los ornatos de la coronación de Carlos III, pero da la fecha 1743 y fue la catedral quien le pagó, según comprobantes de Fábrica, los 2.600 reales (Couselo Bouzas, Galicia artística, p. 642). Todo esto hace sospechar que la obra realizada por Miguel Varela no tiene relación con la encargada por el Consistorio compostelano.

Sobre él véase Morales "Andrés de la Calleja".

AHUS, A.M. 206, f. 244r.

AHUS, A.M. 207, f. 47r.

AHUS, A.M. 209, f. 231r. Así pues, habría sido realizado a lo largo de 1760.

Queremos expresar nuestro agradecimiento a Shírley Rodríguez, del Servicio de Protocolo del Concello de Lugo, por su amabilidad y por habernos facilitado la reproducción fotográfica del retrato que ilustra este artículo. 